\title{
Quality of life and excessive daytime somnolence in children with ADDH
}

\begin{abstract}
Attention Deficit Disorder with Hyperactivity (ADDH) is currently a very highlighted subject, because of its increasing prevalence among children all over the world. An important concern that parents, educators and health professionals have about this disorder is how it affects these children's lives. In order to demonstrate the effects of ADDH in these children's lives, we studied patients from 4 to 12 years old in a private neurological clinic in Campo Grande. We assessed the children's perception of their quality of life (QOL) and whether or not they have Excessive Daytime Somnolence (EDS). The data collect was conducted through two questionnaires: AUQEI, to identify children's QOL based on their own perception, and Epworth Sleepiness Scale (ESS), to analyze the presence of EDS. From the results, we can indicate that children, mostly, have a good perception of QOL (52.7\%) and lack EDS (71.43\%), which is within the expected standards.
\end{abstract}

Keywords: child, quality of life, excessive daytime somnolence, mental health, mental disorders
Volume I Issue 3 - 2017

\author{
José Carlos Souza,' Tayla Campagna de \\ Assis, ${ }^{2}$ Isabela Pierezan Barros ${ }^{3}$ \\ 'Psychiatrist, State University of Mato Grosso do Sul, Brazil \\ ${ }^{2}$ Physical Educator, State University of Mato Grosso do Sul, \\ Brazil \\ ${ }^{3}$ Medical Student, State University of Mato Grosso do Sul, Brazil
}

Correspondence: José Carlos Souza, Psychiatrist, MD, PhD in Mental Health, Professor at State University of Mato Grosso do Sul, Brazil,Email josecarlossouza@uol.com.br

Received: September 23, 2017 | Published: November 21, 2017
Abbreviations: ADDH, attention deficit disorder with hyperactivity; QOL, quality of life; EDS, excessive daytime somnolence; AUQEI, quality of life evaluation scale; ESS, epworth sleepiness scale

\section{Introduction}

QOL is advocated as a way of going further from simply controlling systems to valuing deeper parameters such as mortality, life expectancy and other rates pertaining to people's lives. Thus, in this condition, QOL is the interconnection of the factors that differentiate the daily activities of human beings. ${ }^{1}$ Many natural, psychological and sociocultural factors are associated with this concept, such as: physical health, mental health, longevity, satisfaction at work, family relationships, mood, productivity, dignity and spirituality. ${ }^{2}$

Proving that QOL is also linked to quality of sleep Érico Felden Pereira et al. [3] discovered that poor quality of sleep results in a low capacity to perform daily activities such as work, which also arises pain during the daytime and consequently affects people's quality of life. Due to the lack of sleep resulting in difficulty carrying out daily activities, sleep is considered essential for life. Yet, in most cases, we do not know what this phenomenon is or how it can intervene in our daily lives and especially in our QOL. This fact draws attention to the need for further studies on the subject, such as this one.

According to Driver et al. ${ }^{4}$ a good QOL is also related to the practice of physical exercises, which brings improvement to cognitive aspects, helping in people's mental lives. In this way, physical exercises are able to interfere with the treatment of children with $\mathrm{ADDH}$, who compose the population assessed in this study. ADDH is a subject that is prominent in the media and is present in many current discussions. Despite that, it is often not understood properly by the average population, since everyone claims to know which are the symptoms, diagnoses and treatment of this disturb.
$\mathrm{ADDH}$ is one of the most frequently studied disorders in medicine, yielding increasingly convincing data, even more than other mental disorders and medical conditions. ${ }^{5}$ This type of disorder is present in around $3 \%$ to $7 \%$ of children. ${ }^{6}$

Due to several discussions about medicalization in schools and the visibility of psychodiagnoses and disclosures on ADDH, several researches are found regarding the disorder in the period of childhood and adolescence. This disorder can be considered hereditary, and more cases in the same family may be evidenced, i.e., there are children, adolescents and adults with ADDH in all cultures and ethnical groups. ${ }^{6}$ Do these children with ADDH have less quality of sleep, because they are more physically active and cannot use enough hours of sleep to maintain a standard considered normal? Does this factor actually affect these children's QOL? This study aims at answering those questions.

\section{Materials and methods}

This research was submitted to Plataforma Brasil, a national database where every research with human beings in the country can be found and followed through its stages. It was also submitted to Research Ethics Committee of Dom Bosco Catholic University (UCDB), obtaining authorization to carry out the research, in accordance with resolution N. 466 (December 12, 2012) of the National Council of Health. All participants and their guardians were informed about the study's objectives by reading the consent form before signing it and having the right to withdraw consent for participation at any time during the study. Only the parents signed the Free and Informed Consent Form, since the study population is composed only of children.

This study was conducted in the city of Campo Grande, Mato Grosso do Sul, with children diagnosed with ADDH, and the data were collected in three ways: in a private clinic, in the homes of the respondents, and in the Internet, through electronic mail. 
Population was composed of 26 children who underwent treatment for ADDH in a private clinic. However, only 14 children accepted to participate and met the requirements for participation in our research, corresponding to the study sample. The children who participated in this study, which had been diagnosed with ADDH by the neurologist in charge of the clinic, are aged between 4 and 12 years old and are followed up at the same place. 11 of them were boys and 3 were girls, and none of them had any other chronic disease associated. In order to collect the data regarding the variables in this study, questionnaires were used.

The questionnaire selected to assess QOL in children was the quality of life evaluation scale (AUQEI), which evaluates children aged 4 to 12 years old, Manificant and Dazord, 1997 validated by Assumpção et al. ${ }^{7}$ This instrument evaluates the subjective feeling that a child has about their well-being, relying in the fact that developing individuals are able to express themselves, respecting their subjectivity. It is a self-applied questionnaire, with a low number of questions and no time limit to be answered, since the child should speculate when answering the questions. ${ }^{8}$ The questions correspond to four areas, as shown in Table 1.

Table I Areas appraised in AUQEI

\begin{tabular}{lll}
\hline Area & Description & $\begin{array}{l}\text { Corresponding } \\
\text { questions }\end{array}$ \\
\hline Function & $\begin{array}{l}\text { Related to school } \\
\text { activities, meals, lying } \\
\text { down, seeing doctors }\end{array}$ & $1,2,4,5$ and 8 \\
Family relationships & $\begin{array}{l}\text { Referring to the child's } \\
\text { opinions about the parental } \\
\text { figure and oneself }\end{array}$ & $\begin{array}{l}3,10,13,16 \\
\text { and } 18\end{array}$ \\
& $\begin{array}{l}\text { Related to holidays, } \\
\text { birthdays and relationship } \\
\text { with grandparents }\end{array}$ & 11,21 and 25 \\
& $\begin{array}{l}\text { Related to independence, } \\
\text { relationship with peers and } \\
\text { school assessments }\end{array}$ & $15,17,19,23$ \\
Autonomy & and 24 \\
\hline
\end{tabular}

Questions 6, 7, 9, 12, 14, 20, 22 and 26 are not included in these factors, because they have isolated importance, once they represent areas separated from the others. Each of these questions has a score ranging from 0 (zero)- very unhappy- to 3 (three)- very happy. The maximum score that can be obtained is equal to 78 points. According to the validation article, ${ }^{7}$ the cutoff grade was 48 points, that is, if the result is below this number, the child's QOL is classified as unsatisfactory (impaired QOL) and if it is above this score, QOL is considered good.

As for EDS, we used ESS, ${ }^{9}$ which is a self-administered questionnaire that evaluates the possibility of the individual napping in certain daily situations. For this evaluation, each child answered questions that had a scale ranging from 0 (zero) to 3 (three) points, in which 0 (zero) matches with no probability of snoozing and three corresponds to a large possibility of snoozing during the day. If the total score is greater than 10 points, it is possible to identify individuals with EDS, and if this score is greater than 16, it indicates that drowsiness is more severe, demanding treatment in those cases. Low scores correspond to another sleep disorder, such as insomnia, revealing low probability of the individual sleeping, even when they are in a relaxed state.
Statistical analysis was performed considering the database as independent variables in nominal and ordinal scales. The first investigation was of an exploratory nature, through descriptive statistics. It was separated by sex, QOL and EDS. Age was not considered, since the sample allows us to classify all of the children as a single category. For correlation of the variables, the Chi-square test, suitable for qualitative variables with two or more categories, was used to measure the degree of discrepancy between the set of observed frequencies.

\section{Results and discussion}

Results obtained for QOL, both overall and divided by sex, are shown in the table below:

As seen in Table 2, the general average of QOL is within the expected standards, therefore, the general perception of the children regarding quality of life is considered as good. However, it should be noted that the minimum grade found was 38 points, which is below the standard cutoff grade.

Table 2 Quality of life evaluation scale (AUQEI) score

\begin{tabular}{lllll}
\hline Area & N & Minimum & Maximum & Average \\
\hline Score & 14 & 38 & 63 & 52,7 \\
Boys & 11 & 38 & 60 & 51,8 \\
Girls & 3 & 51 & 63 & 56 \\
\hline
\end{tabular}

In what concerns the average separated by sex, the results show that girls have a better perception of QOL than boys, as they present a total average of 56 points, while boys present 51.8 points. Boys had the lowest grade found ( 38 points) and girls had the highest (63 points). Nevertheless, these conclusions are not necessarily reliable, once our sample consisted of a small and insufficient number of girls.

Regarding QOL according to the child's sex, three boys presented a QOL considered bad, representing a total of $27.27 \%$. Although there were boys with this result, most of them fit within a good perception of QOL, resulting in $72.73 \%$ (8 boys). However, no girl obtained a QOL grade considered bad, that is, $100 \%$ of the girls believe that their QOL is classified as good.

Concerning the areas of AUQEI questionnaire, which are: function (questions 1, 2, 4, 5 and 8) family relationships (questions 3, 10, 13, 16 and 18), leisure (questions 11, 21 and 25), autonomy (questions 15, 17, 19, 23 and 24) and isolated answers (questions 6, 7, 9, 12, 14, 20, 22 and 26), we obtained the following results, as shown in Table 3.

Table 3 General description of quality of life in its areas

\begin{tabular}{llllll} 
Area & N & Minimum & Maximum & Average & Frequency \\
\hline Function & 14 & 5 & 14 & 9,5 & $63 \%$ \\
Family & 14 & 7 & 15 & 11,7 & $78 \%$ \\
relationships & 14 & 6 & 9 & 7,7 & $86 \%$ \\
Leisure & 14 & 4 & 12 & 8,2 & $54,7 \%$ \\
Autonomy & 14 & &
\end{tabular}

As shown in the table above, the area with the highest grade found, corresponding to $86 \%$ of the obtained score, is leisure, which relates to holidays, birthdays and relationships with grandparents, and the area with the lowest grade found, corresponding to $54.7 \%$ of the obtained score, refers to autonomy, which deals with questions related to independence, relationship with peers and school evaluations. The areas function and family relationships appear with an average considered good, since they present results above the median of 
frequency, representing a total of $63 \%$ and $78 \%$, respectively. These areas concern issues related to school, meal, seeing doctors and children's opinions regarding parents and themselves.

Regarding the three questionnaires responded by the participants with perception of poor QOL, the area with the highest grade was related to leisure $(66.6 \%)$, followed by family relationships $(59.96 \%)$. The areas with the lowest grades were those related to function (39.96\%) and autonomy (also with 39.96\%).

The fact that autonomy appears only in children from the age of 11 gives a possible explanation for this area having the lowest score.

\section{When we separate the areas by sex, we obtain the following data}

According to what is observed in Table 4, girls obtained the highest averages, highlighting the areas of family relationships and leisure. Only in autonomy the maximum grade was found for boys, since in the rest of the areas, the maximum grades were found for girls. It is relevant that autonomy was the one area to obtain the lowest scores, since the maximum grade found was 15 points, and the averages, both male and female, distanced themselves from this grade more than from the other averages by areas. The highest grade found for both sexes was in leisure, since the maximum score obtained was 9 points, and the averages, both male and female, were close to this score. However, it can be seen that the children's QOL was classified as being good, and the girls had a better perception of their QOL, giving a positive highlight to leisure, which obtained the best score within the questionnaire, and negative highlight for autonomy, which obtained the lowest score of the study.

In the case of EDS, Epworth scale had a general average score of 5.64 points, which shows that the population in evidence in this study does not present this disturb, once an individual has to obtain a score equal to or above 10 points to be classified as having EDS, as shown in Table 5 .

Through the table, it is possible to verify that there was a great

Table 4 Comparison of the areas of quality of life between the sexes

\begin{tabular}{lllllll}
\hline \multirow{2}{*}{ Area } & \multicolumn{7}{l}{ Male } & \multicolumn{5}{c}{ Female } \\
\cline { 2 - 7 } & Minimum & Maximum & Average & Minimum & Maximum & Average \\
\hline Function & 5 & 13 & 9,4 & 7 & 14 & 9,5 \\
Family & 7 & 15 & 8,5 & 12 & 15 & 11,7 \\
relationships & 5 & 9 & 7,5 & 8 & 9 & 8,6 \\
Leisure & 5 & 12 & 8 & 7 & 10 & 8,2 \\
Autonomy & 4 & & & & & \\
\hline
\end{tabular}

Table 5 Epworth somnolence scale: general

\begin{tabular}{lllll}
\hline Area & N & Minimum & Maximum & Average \\
\hline Score & 14 & 0 & 14 & 5,64
\end{tabular}

Table 6 Correlation between quality of life and excessive daytime somnolence

\begin{tabular}{lll}
\hline \multirow{2}{*}{ Area } & \multicolumn{2}{l}{ Excessive daytime somnolence } \\
\cline { 2 - 3 } & Yes & No \\
\hline Poor quality of life & 0 & 3 \\
Good quality of life & 4 & 7 \\
Total & 4 & 10 \\
\hline
\end{tabular}

According to the Table 3 children obtained poor QOL, but did not present EDS disorder. Still according to the Table 4 children with better perception of QOL do not have the disorder. highest scores, which also occurred in this study. variation between minimum and maximum scores, corresponding to 14 points, which demonstrates that the population is heterogeneous regarding these results; that is, within the same population, there are people who do not feel the need of sleeping in the situations listed and others who cannot control the desire to take a nap under the same conditions.

Out of the fourteen questionnaires analyzed, four had a score equal to or greater than the cutoff grade (10 points), demonstrating that four children in the population had EDS, which represents $28.57 \%$ of the population. No case obtained a score higher than 16 points, which could reveal very severe somnolence, or even a probability of narcolepsy.

Another result that requires a great deal of attention is the fact that four children had scores equal to zero on the scale, indicating that there is no drowsiness. However, they may have other sleep disorders, since the excessively low score can reveal a tendency for sleep deprivation, such as insomnia.

In what concerns EDS in relation to sex, it can be seen that the average obtained by the boys is within the standard considered normal, but the range between maximum and minimum scores is very large, and some boys may have disorders of both EDS and deprivation of sleep. Out of the eleven boys studied, only one presented EDS, representing a total of $9 \%$ of the population.

Regarding to girls, all of them were classified with EDS, obtaining a high average equivalent to 11.6 points, that is, $100 \%$ of the female population presents the disorder. It is also noticed that between the minimum and the maximum score found there is no great range as seen in the data referring to the boys, demonstrating a greater homogeneity among the girls.

When Chi-Square test was used to compare sex with EDS, it was noted that there was a significant difference between the variables, i.e., there is a dependence between gender and sleepiness $(p<0.005)$. Concerning the correlation of the study variables, the following results are obtained, as shown in Table 6 .

good QOL presented the disorder and 7 children with good QOL did not present EDS. Thus, it was verified that there is no dependence between the variables according to Spearman's Chi-Square test. However, it can be stated that $50 \%$ of the population does not have EDS and has good QOL, affirming the hypothesis that children with

In 2000, Assumpção et al. $^{7}$ in the validation of the AUQEI questionnaire, applied it in a sample of 353 children, and obtained a general average of 521 points, that is a perception of QOL considered as good, still obtaining significant difference between the sexes. The authors also concluded that the female population presented the 
In the study of Bilhar ${ }^{10}$ conducted with a sample of 88 children without previous treatment for the disorder, who were referred to the Learning Disorders Ambulatory of the Children's Institute, it was observed that they had impairments in QOL, in emotional, social, educational and psychosocial aspects, besides total QOL. This information is different from those found in our study, in which the majority of the children presented good QOL. Although Bilhar's study had a much larger population, what seems to be more interesting to explain the rates of QOL found in this study is the length of treatment that the children received. The majority of the children in our study have been receiving medical care for two years or more, while the population studied by Bilhar did not have previous treatment, which already changes the children's condition and consequently their lifestyle. ${ }^{10}$

Lima et al. ${ }^{11}$ conducted a study with a sample composed of 232 children, 89 of them attending a full-time school (school A) and 143 attending a part-time school (school B). They observed that in school A, a better perception of QOL was obtained, reaching $81 \%$, while school B presented 58\%. This evidence shows that the more involved with projects, diversified activities or pedagogic activities the child is, the better they can develop their social, physical and intellectual potentialities, positively impacting their QOL. In the case of this study with children with ADDH, full-time school could be a way of trying to occupy their time, so that they learn to focus their attention. Along with the use of medication and therapy, these could control their disorder better, so that their QOL can also be perceived as more positive, leading to an improvement in their lifestyle.

In the present study and also in the studies pointed out for discussion, perception of children's QOL has a general average classified as positive, that is, according to the children's personal view, their quality of life is good. Regarding the areas of QOL, Bilhar found in her study that leisure is the factor with the highest score, ${ }^{10}$ because it concerns issues related to recreation and contact with grandparents. This finding can be explained by the age of the children, who tend to enjoy playing and spending time with grandparents. Children's age also explain why they present more difficulty in autonomy, which is related to the difficulty of organizing the child's tasks and activities and maintaining personal objects in order, in a way they end up performing disorganized and sloppy work, being unable to manage the time for activities they participate in, and also finding it difficult to meet deadlines. ${ }^{12}$

In the study of Lima et al., ${ }^{11}$ the areas of greatest satisfaction were leisure and family relationships, and the one with the lowest result obtained was autonomy, which makes even clearer that family and presence of parents in children's lives are very significant, since this is a condition that makes them safer and more satisfied. The relevance of leisure in the child's life is also highlighted, since the highest scores for questions were obtained in this area.

Assumpção et al. ${ }^{7}$ also found in their research that leisure was the area with higher scores and autonomy with lower scores, results that are similar to those found in this study and in other studies described above. Therefore, it can be seen that in all the studies described above, the areas of leisure and family relationships obtained the best results, whereas autonomy obtained the lowest grades. This shows that the result we obtained is within the expected, since most children feel happy when it comes to leisure, because it is a space destined to moments of recreation and play, but feel unsatisfied on issues related to autonomy, as they still depend heavily on parents and caregivers, due to the difficulties they find when organizing their tasks and activities, as highlighted by the new. ${ }^{12}$

In what comes to autonomy, the first idea related to this concept is the existence of an independent individual, who can carry out their activities without help or assistance of other people. Piaget ${ }^{13}$ considers autonomy as referring to a fundamental idea within the educational context, thus constituting a purpose for education. Pereira ${ }^{14}$ adds that autonomy is related to the capacity of self-regulation, both morally and intellectually, freeing children from the beliefs that are imposed by older people and replacing the rules of authority with the existence of consciousness.

Regarding EDS, Sena et al..$^{15}$ in their study with a sample of 140 obese children and adolescents aged 5 to 18 years old, the disturb was present in $19.3 \%$ of the cases, a total of 27 children, a lower result than the one found in this study. Similar results were found in a study by Sobrino, ${ }^{16}$ in which adolescents of both sexes aged up from 10 years old, presented EDS only in $13.7 \%$ of the sample.

Petry et al. ${ }^{17}$ carried out a study with a sample composed of 3049 schoolchildren aged 9 to 14 years old, enrolled in public schools in the city of Uruguaiana, RS. Results were that $8 \%$ of the population presented EDS, associated with habitual snoring, obstructive sleep apnea, daytime oral breathing and poor school performance.

In a study by Pereira ${ }^{18}$ with high school students, aged 13 to 21 years old, a higher percentage was demonstrated, with $25 \%$ of the sample presenting EDS, with the girls having the highest scores. Villaça ${ }^{19}$ conducted a study with a sample ranging from newborns to adolescents with 17 years and 11 months of age who had at least one clinical complaint of neuromuscular, behavioral, interpersonal or pedagogical nature that is compatible with muscular dystrophy, and found that $75 \%$ of the sample presented the disorder. Therefore, it was verified that these exposed studies showed a higher rate of EDS than what we found in this research.

With these results, it is noticed that among the populations presented in the studies, the minority presents EDS, that is, in what comes to the uncontrollable desire to sleep during the day, the children are in a good mood, being able to control or not even feeling such will during their daily activities. In a study by Ferreira, ${ }^{20}$ with children aged 2 to 12 years old, admitted to a university hospital in Belém, Pará, who underwent adenotonsillectomy, ESS was applied before and after surgery. The result before the surgery was an EDS average of 9.9 points, showing that $50 \%$ of the sample had this disorder. After surgery, this number decreased, with an average of 8 points that meant only $30 \%$ of the population still had EDS, demonstrating a large number of children with this disorder, unlike the results found in the studies mentioned above.

In the study by Ferreira, ${ }^{20}$ girls and boys obtained the same average for EDS, showing that the population studied was predominantly homogeneous and did not show any significant variation between the results when separating by sex. In the study by Sena et al., ${ }^{15}$ EDS showed a higher average for girls, being present in $76.9 \%$ of the female population. Amaral ${ }^{21}$ found a result that $33.1 \%$ of the assessed sample had EDS, and that girls presented a higher score and a higher risk than boys of developing the disorder. These results demonstrate a reality that was also found in this study, since the female gender also obtained the highest scores and average for EDS. 
According to Érico Felden Pereira et al., ${ }^{22}$ few studies approaching sleepiness and children are found in the literature, especially in what concerns Brazilian population. However, some studies stand out, including Souza et al. ${ }^{8}$ in which 378 adolescents with medium age of 16.5 years old were assessed, and Petry et al. ${ }^{17}$ This is due to the fact that EDS is not easily diagnosed in children, especially in the age covered in this study (4 to 12 years old), since they are predominantly unable to describe EDS symptoms spontaneously. ${ }^{15}$ Therefore, comparison between the results obtained by this study and the existing data in the literature becomes more difficult, making it possible to only present and analyze the data descriptively. More research in the area is necessary to establish national parameters regarding the subject. ${ }^{22}$ It is also important to emphasize sleeping well, because it is during this stage of the day that some functions of our body are renewed. During sleep, the organism brings back the condition in which the day started, implying a restorative effect in our tissues, in addition to other homeostatic processes such as thermoregulation. It is also stated that consolidation of memory and learning acquired during the day occurs through sleep. ${ }^{23}$

\section{Conclusion}

The present study found that the general average QOL is of 52.7 points for children, a result that is above the established cutoff grade (48 points), showing that QOL of the sample is considered good. In what comes to EDS, the overall average for the children was 5.64 points, characterizing a sample without this disturb. According to the correlation of variables, children with better perception of QOL are less likely to present EDS, stating one of the hypotheses raised at the beginning of the study, which demonstrates the importance of having good quality of sleep in order to have better QOL. This study had a small sample, with few participants involved, so its goals were presenting and understanding the phenomenon of QOL and EDS in patients with ADDH and, therefore, encouraging more research in the subject, that will enable verification of these variables with a larger population that represents a greater proportion in the ADDH scenario.

\section{Acknowledgements}

None.

\section{Conflicts of interest}

The authors declared that there are no conflicts of interest.

\section{References}

1. Maria claudia roberta tombolato. Qualidade de vida e sintomas psicopatológicos do estudante universitário trabalhador. Brazil: Pontifical Catholic University of Campinas; 2005.

2. Anita Liberalesso Neri. Qualidade de vida e idade madura. 7th ed. Campinas, Brazil: Papirus Editora; 1993.

3. Pereira EF, Teixeira CS, Kothe F, et al. Sleep quality and quality of life perception in orchestra musicians. Rev psiquiatr Clín. 2010;37(2):48-51.

4. Driver HS, Taylor SR. Exercise and sleep. Sleep Med Rev. 2000;4(4):387402 .

5. Paulo Mattos. No mundo da Lua: perguntas e respostas sobre transtorno de déficit de atenção com hiperatividade em crianças. Adolescentes e adultos. 4th ed. São Paulo, Brazil: Lemos; 2003.
6. Alexandra Amadio Belli. TDAH! E agora? A dificuldade da escola e da família no cuidado e no relacionamento com crianças e adolescentes portadores de Transtorno de Déficit de Atenção/Hiperatividade. São Paulo, Brazil: Editora STS; 2008.

7. Assumpção Júnior FB, Evelyn Kuczynski, Sprovieri MH, et al. Escala de avaliação de qualidade de vida: (AUQEI-Autoquestionnaire Qualité de Vie Enfant Imagé) validade e confiabilidade de uma escala para qualidade de vida em crianças de 4 a 12 anos. Arq Neuropsiquiatr. 2000;58(1):119-127.

8. Souza JGS, Pamponet MA, Tamirys Caroline S Souza, et al. Instrumentos utilizados na avaliação da qualidade de vida de crianças brasileiras. Rev Paul Pediatr. 2014;32(2):272-278.

9. Ann Johns. English for specific purposes: Its history and contribution. Heinle, et al. editors. Boston, USA: 1991. p. 67-77.

10. Juliana Cristina Fernandes de Araújo Bilhar. Qualidade de vida de crianças com transtorno de déficit de atenção/hiperatividade. Brazil: University of São Paulo; 2010.

11. Lima CHF, Souza DG, Neiva CM, et al. A influência da escola de tempo integral sobre a qualidade de vida infantil. Revista Digital. 2014;18(190).

12. Diagnostic and Statistical Manual of Mental Disorders. Arlington, USA: American Psychiatric Association; 2013.

13. Jean Piaget. O juizo moral da criança. Summus. São Paulo, Brazil; 1932.

14. Regiane Larréa Pereira. O papel da educação infantil na construção da autonomia moral: uma revisão da literatura. Brazil: Federal University of Rio Grande do Sul; 2006

15. Sena ASS, Cardoso AS, De Carvalho DF, et al. Sonolência diurna excessiva e fatores de risco cardiometabólicos em crianças e adolescentes com excesso de peso. Journal of Human Growth and Development. 2013;23(1):24-30.

16. Gazini Sobrino CC. Sono e Qualidade de vida em adolescentes infectados pelo virus da imunodeficiência humana. Brazil: University of Campinas; 2011.

17. Carine Petry, Pereira MU, Pitrez PMC, et al. Prevalência de sintomas de distúrbios respiratórios do sono em escolares brasileiros. $J$ Pediatr. 2008;84(2):1-7.

18. Érico Felden Pereira. Sono e sonolência diurna excessiva em adolescentes do Ensino Médio. Brazil: Federal University of Paraná; 2011.

19. Ana Teresa Vieira Villaça. Avaliação neuromuscular e neuropsicológica na distrofia miotônica congênita infantil e juvenil. Brazil: State University of Campinas; 2004.

20. Marcos Vinicius Santos Ferreira. Avaliação da escala de sonolência de Epworth no pré e pós operatório de crianças submetidas à adenoamigdalectomia. Brazil: Federal University of Pará; 2010.

21. Maria Odete Pereira Amaral. Epidemiologia da insônia em adolescentes do diagnóstico de situação à intervenção. Portugal: University of Lisbon; 2013.

22. Pereira EF, Teixeira CS, Louzada FM. Daytime sleepiness in adolescents: prevalence and associated factors. Rev Paul Pediatr. 2010;28(1):98-103.

23. http://www.institutobrasileirodosono.com.br/index.php 